\title{
Grupo de trabalho 4 - A natureza da interdisciplinaridade na reflexão do planejamento urbano e regional a visão dos órgãos de fomento e apoio a pesquisa
}

\begin{abstract}
Os desafios para a construção de novos paradigmas de produção de conhecimento na perspectiva da transdisciplinaridade
\end{abstract}

\footnotetext{
- O campo de planejamento urbano emerge marcado pela interdisciplinariedade tendo em vista o seu objeto, centrado no Estado e na construção do espaço urbano e regional. Apesar dos avanços na perspectiva da interdisciplinaridade, os paradigmas hegemônicos de produção do conhecimento não conseguem romper com uma visão simplificadora da realidade no contexto de um mundo cada vez mais complexo. Assim, o desafio contemporâneo estaria ligado a adoção da transdisciplinaridade na produção do conhecimento no campo do planejamento urbano e regional, ou seja, a adoção de um novo paradigma de produção de conhecimento capaz de interpretar a complexidade do mundo contemporâneo.
}

- Diferentemente da interdisciplinaridade, que fundamentalmente estaria referida a interação entre várias disciplinas visando a produção de um novo conhecimento, a transdisciplinaridade representaria um novo sistema de produção de conhecimento, marcado pela ausência rígida entre as disciplinas, construído a partir de novos paradigmas.

\author{
SíNTESE DA DISCUSSÃO DA MESA 4
Orlando Alves dos Santos Junior \\ SÍNTESE DA DISCUSSÃO DA MESA 4
Orlando Alves dos Santos Junior
}

- Aquestão central que emerge da reflexão é que a questão da interdisciplinariedade deixaria de ser uma tarefa individual de cada profissional para se constituir, como transdisciplinaridade, numa tarefa coletiva. Poder-se-ia perguntar, nesta perspectiva, quais seriam as tarefas coletivas postas para a área de planejamento urbano e regional?

\section{As diferentes visões em torno da in- terdisciplinaridade na área do plane- jamento}

- Percebe-se que não existe apenas uma visão em torno da interdisciplinaridade. A falta de consenso ou mesmo a disputa entre diferentes visões acerca da interdisciplinaridade também atravessam a própria área de Planejamento Urbano e Regional e Demografia.

- Essa diferentes concepções em torno da interdisciplinaridade na área de planejamento se manifestam em diferentes contextos e períodos históricos. Ou seja, existem diferentes abordagens interdisciplinares visando apropriar o conhecimento de diferentes disciplinas, que se alteram em função da trajetória e particularidade de cada curso. 
- Se há uma compreensão comum de uma "interdisciplinaridade própria" da Área essa estaria fundamentalmente baseada na aceitação de uma variedade de abordagens metodológicas "interdisciplinares" que não teria necessariamente na sua origem uma procura explícita de ultrapassar e superar métodos disciplinares a partir de determinado objeto, mas seria resultado de um processo mútuo e interativo presente na prática do ensino e pesquisa da área.

- A reflexão apontaria para a necessidade de superar a interdisciplinaridade de forma dialética, avançando na reflexão em torno da relação entre objeto e sujeito de conhecimento.

- Bastaria afirmar as diretrizes para a produção de um conhecimento interdisciplinar ou transdisciplinar da área de planejamento urbano e regional, ou seria necessário pensar em arranjos de gestão dos programas que, de certa forma, institucionalizasse a interdisciplinariedade ou propiciassem a construção de novos paradigmas na direção da transdisciplinaridade? Caso se aceite a ideia da institucionalização da interdisciplinariedade pelos programas, caberia refletir sobre as diretrizes e os desenhos institucionais que poderiam ser adotados nessa perspectiva

\section{A interdisciplinaridade na lógica pro- gramática do planejamento urbano e regional: a extensão e os desafios na área da formação}

- As experiência em torno da formação tem acionado diferentes modalidades de práticas interdisciplinares.

- Da mesma forma, as pesquisa aplicadas as políticas públicas desenvolvidas pelo governo federal, em especial, o Ministério das Cidades, tem estimulado a incorporação de uma visão interdisciplinar.

- No entanto, a reflexão em torno da interdisciplinaridade e da transdisciplinaridade ainda parece estar fundamentalmente focada na questão da produção de conhecimento, sem problematizar a relação entre ensino, pesquisa e extensão.

\section{A Interdisciplinaridade na Perspectiva dos Órgãos de Fomento}

- A área de planejamento urbano e regional ainda tem uma participação relativamente muito pequena no quadro geral de financiamento do CNPq, que além de tudo se mostra muito concentrada na região sudeste.

- A questão que emerge desse quadro, são os desafios postos para a ANPUR no sentido de fortalecer o peso da área de planejamento na política de financiamento das agência de fomento e garantir uma maior democratização regional dos aportes financeiros. 

